\section{Review: day hospital is not more effective than inpatient care but is associated with modest cost savings in acute psychiatric disorders}

Marshall M, Crowther R, Almaraz-Serrano A, et al. Day hospital versus admission for acute psychiatric disorders. Cochrane Database Syst Rev 2003;(1):CD004026 (latest version Nov 19 2002).

\section{QUESTION: In patients with acute psychiatric disorders, what is the effectiveness of day hospital compared with inpatient care?}

\section{Data sources}

Studies were identified by searching the Cochrane Library (Issue 4, 2000), Medline (1966 to December 2000), CINAHL (1982 to December 2000), EMBASE/ Excerpta Medica (1980 to December 2000), PsycLIT (1967 to December 2000), and bibliographies of relevant articles. Researchers were contacted to identify unpublished studies.

\section{Study selection}

Randomised controlled trials of acute psychiatric day hospital compared with standard inpatient care for patients with acute psychiatric disorders (all diagnoses) were selected. Studies were excluded if a majority of participants were $<18$ or $>65$ years of age, or if participants had substance abuse or organic brain disorder.

\section{Data extraction}

Data were collected on study quality, patients, feasibility of day hospital treatment, extent of hospital care, clinical and social outcomes, and costs of care.

\section{Main results}

9 trials (1568 patients) met the selection criteria. Follow up durations ranged from 2-24 months. Sample sizes ranged from 90-378 participants. Individual patient data was obtained for 4 trials (486 patients) Patients allocated to day hospital care had a longer duration of index admission than those allocated to inpatient care (table). Day hospital and inpatient care did not differ for the total number of days in hospital (table). In 5 trials (667 patients), no difference existed between day hospital and inpatient care for rates of readmission to day or inpatient care after discharge $(\mathrm{p}=0.4)$. In 1 trial $(160$ patients), no difference existed between day hospital and inpatient care for all cause mortality rates $(\mathrm{p}=0.7)$. Of 5 trials reporting costs of care, 4 trials reported that day hospital care was associated with lower costs for all psychiatric care (including hospital care) than inpatient care (cost reductions ranged from 21-37\%), and 1 trial found no cost difference.

\section{Conclusions}

In patients with acute psychiatric disorders, day hospital is associated with a longer duration of index admission and is not more effective in reducing readmission rates or total number of days in hospital. Day hospital care is associated with cost savings between $21 \%$ and $37 \%$ of inpatient care.

Source of funding:

NHS Health

Technology Assessment.

For correspondence:

Dr M Marshall,

Department of

Community Psychiatry,

University of

Manchester, Preston,

UK

mmarshall@man.ac.uk

Abstract also appears

in Evidence-Based

Nursing.

Day hospital $v$ inpatient care in acute psychiatric disorders at 2-24 months

\begin{tabular}{llll} 
Outcomes & $\begin{array}{l}\text { Number of } \\
\text { trials }\end{array}$ & $\begin{array}{l}\text { Number of } \\
\text { patients }\end{array}$ & $\begin{array}{l}\text { Weighted mean } \\
\text { differences }(95 \% \mathrm{Cl})\end{array}$ \\
$\begin{array}{c}\text { Duration of index admission } \\
\text { (days) }\end{array}$ & 3 & 465 & $10.9(1.09$ to 20.7$)$ \\
\hline $\begin{array}{c}\text { Total number of days in } \\
\text { hospital (days/month) }\end{array}$ & 3 & 465 & $-0.38(-1.32 \text { to } 0.55)^{*}$ \\
\hline
\end{tabular}

*Not statistically significant.

\section{COMMENTARY}

In the UK and elsewhere, it is government health policy to reduce reliance of mental health services on inpatient units. ${ }^{1}$ However, as bed numbers are reduced, the levels of psychiatric activity ${ }^{2}$ and morbidity ${ }^{3}$ are increasing with the inevitable consequence that patients gaining inpatient admission are a relatively homogenous group of the most acutely ill.

Thus, it is important to compare the effectiveness and costs of inpatient admission with those of potential alternatives such as the acute day hospital. The review by Marshall et al identified 73 studies, only 9 of which met the specified inclusion criteria. On the basis of this limited number of studies, the review found acute day hospital to be capable of reducing inpatient admission by about $25 \%$, at a cost saving of similar magnitude.

The studies included in the review were published over a period of 31 years (196496) when, as noted, patterns of both psychiatric morbidity and mental health service provision were changing. ${ }^{2-3}$ It is difficult, therefore, to be sure that the earlier comparisons would remain valid today: the greater clinical complexity and higher prevalence of dual diagnosis in current inpatient populations might be expected to widen the gap between these patients and those suitable for day hospital care.

A further limitation of the chosen studies is the problem of converting their costs to a common base rate for comparison. In any case, it is unclear whether all relevant resources and outcome measures were identified and costed, as would be necessary for a cost effectiveness analysis.

Finally, only 1 study included data on patient satisfaction. In view of the strongly expressed views of both patients and advocacy groups ${ }^{4}$ that inpatient wards do not provide a therapeutic milieu, it is likely that most patients would prefer their acute episode to be managed via a day hospital than inpatient admission. However, this hypothesis remains to be fully tested.

Teifion Davies, PhD MRCPsych Guy's, King's and St Thomas' School of Medicine London, UK

1 Department of Health. National service framework for mental health. London: Department of Health, 1999.

Double D. The limits of psychiatry. BMJ 2002;324:900-4

3 Fitzpatrick NK, Thompson CJ, Hemingway H, et al. Acute mental health admissions in inner London: changes in patient characteristics and clinical admission thresholds between 1988 and 1998. Psychiatric Bulletin 2003:27:7-11.

4 Mind. Evidence to the health committee inquiry on provision of NHS mental health services. London. Mind, 2000. http://www.mind.org.uk 